\title{
Antihemophilic Globulin (Factor VIII) Activity of Human Fibrinogen*
}

\author{
J. T. Sgouris, L. A. Hyndman and J. A. Penner \\ Division of Laboratories, Michigan Department of Health, Lansing, Mich. and \\ Department of Internal Medicine, Simpson Memorial Institute, The University \\ of Michigan, Ann Arbor, Mich.
}

Antihemophilic globulin (AHG; Factor VIII) activity has been reported to deteriorate rapidly in blood stored at $+1^{\circ} \mathrm{C}$ to $6^{\circ} \mathrm{C}[4,8]$. Because of this, Factor VIII-rich fibrinogen (Fraction I of CoHN $e t$ al. [3]), is prepared from fresh blood and processing to the frozen state is completed within $24 \mathrm{~h}$ following donation. On the other hand, Brinknous et al. [2] found $37 \%$ of the activity remaining after 21 days. Bowie, Thompson and Owen [1] found that one-half the normal level of Factor VIII activity was still present after 21 days of storage at $4^{\circ} \mathrm{C}$. In this communication we show that clinically effective amounts of Factor VIII activity are also present in certain lots of dried fibrinogen (human) prepared from outdated citrated whole blood (21 days or older).

Eighteen lots of human fibrinogen were assayed in vitro for their Factor VIII content by determining their ability to shorten the prolonged clotting time of recalcified hemophilic plasma, using a method by Nilsson, Blomback and von Francken [5]. The assay system consisted of $0.1 \mathrm{ml}$ hemophilic plasma, $0.1 \mathrm{ml}$ of a reference standard Factor VIII preparation (or fibrinogen in various dilutions) and $0.1 \mathrm{ml}$ of $0.03 \mathrm{M} \mathrm{CaCl}_{2}$. The reference standard Factor VIII preparation was a lot of dried antihemophilic globulin (M.D.H. No.83). Fifty milligram (dry weight) aliquots of this reference material and of the test lots of dried fibrinogen were reconstituted in $5 \mathrm{ml}$ saline

- This work was financed, in part, with funds and material provided under an agreement between the American National Red Cross and the Michigan Department of Health Laboratories.; the Michigan Heart Association and Public Health Service Grant 5 M 01-FR 42-05.

Submitted for publication May 20, 1965. 
and assayed at dilutions in saline of $1 / 10,1 / 20,1 / 50$ and 1/100. The clotting time of the recalcified plasma at $37^{\circ} \mathrm{C}$ was determined for each dilution of fibrinogen and of the standard and was plotted on log-log paper (clotting time versus dilution). Straight parallel lines were obtained. The antihemophilic potency of the test fibrinogen lots was established by comparing the dilutions of the unknown and the reference Factor VIII preparation which gave identical plasma clotting times. The Factor VIII standard was assigned a "potency" value of 100 , based on the following: One-hundred milligrams of standard Factor VIII protein was found to contain the antihemophilic factor activity equivalent to $3.8 \mathrm{ml}$ of fresh normal human plasma. The relative potencies of the various lots of fibrinogen are given in Table $I$.

TABLE I

Factor VIII Activity of Fibrinogen Prepared from Outdated Blood

\begin{tabular}{cccccc}
\hline Lot No. & \% Standard & Lot No. & $\%$ Standard & Lot No. & \% Standard * \\
\hline 1 & 50 & 8 & 89 & 15 & 85 \\
2 & 178 & 9 & 15 & 16 & 162 \\
3 & 154 & 10 & 32 & 17 & 86 \\
4 & 51 & 11 & 29 & 18 & 35 \\
5 & 67 & 12 & 10 & & \\
6 & 86 & 13 & 25 & Average & 75 \\
7 & 92 & 14 & 90 & & \\
\hline
\end{tabular}

* = $\frac{\text { units } / \mathrm{mg} \text { Protein fibrinogen lots }}{\text { units/mg Protein Factor VIII standard }} \times 100$

It can be seen from Table I that 12 of the 18 lots of fibrinogen prepared from outdated blood had $50 \%$ or more of the activity of the Factor VIII reference standard which was made from fresh blood. Three lots $[2,3,16]$ had considerably greater activity than the reference and three lots $[7,8,14]$ had activities close to that of the reference. The average activity of the 18 lots was $75 \%$ of the reference standard. Production lots of antihemophilic globulin prepared in the same manner as fibrinogen but from fresh plasma have an average activity equivalent to the standard. 
In vitro assays for antihemophilic activity based on the correction of the prolonged recalcified clotting time of hemophilic plasma may not necessarily reflect the clinical value of the product following administration to hemophiliacs. Therefore, the clinical value of three of these fibrinogen preparations (lot Nos. 1, 8 and 16) was evaluated in classical hemophiliacs admitted to The University of Michigan Hospital, Ann Arbor, Mich. The prothrombin activation rate [6] was used to measure Factor VIII activity in vivo using plasma samples recovered following intravenous administration. All three lots produced in vivo activity that was $50-75 \%$ of that produced by administering an equal amount of either a) a routine antihemophilic globulin product, or b) a commercially available fibrinogen containing antihemophilic globulin, or c) the equivalent volume of fresh plasma [7]. These clinical data further confirm that some of the fibrinogen lots routinely prepared by our laboratories from outdated blood do have significant antihemophilic activity.

The large variation from lot to lot in the Factor VIII activity of our fibrinogen product may be attributed in part to the variable conditions of storage of the whole blood and the Fraction I subsequently separated from it. In some cases, the Fraction I paste that had been used in producing the lots of fibrinogen cited above had been stored for extended periods at $-20^{\circ} \mathrm{C}$. When the Fraction I paste is suspended in final buffer, processing is rapid until the product is frozen prior to drying in vacuo. The holding period prior to drying is purposely kept short. Undoubtedly, other as yet unrecognized factors may influence the final antihemophilic potency of these routine lots of fibrinogen.

Factor VIII-rich fibrinogen (antihemophilic globulin-human) is in short supply and is quite expensive. It would appear from our data that about two-thirds of the fibrinogen preparations made by the Michigan Department of Health from outdated blood contain 50\% or more of the Factor VIII activity of our reference lot made from fresh blood. The more potent of these lots may be considered for use in bleeding episodes in hemophiliacs when Factor VIII concentrates from fresh plasma are not available. Finally, it seems to us that other large stockpiles of Fraction I (fibrinogen) made from outdated blood should be screened and studied in an attempt to determine their value as potential sources of satisfactory Factor VIII preparations for the treatment of bleeding episodes in hemophiliacs. 


\section{Acknowledgments}

The technical assistance of Mr. Harold Galdick, Mr. John Mercer and Mr. Thomas Bartshe is gratefully acknowledged by the authors.

\section{References}

1. Bowie, W. E. J.; Thompson, J. H., Jr. and Owen, C. A., Jr.: The stability of antihemophilic globulin and labile factor in human blood. Proc. Mayo Clin. 39: 144 (1964).

2. Brinkhous, K. M.; Penick, G. D.; Langdeli, R. D.; Wagner, R. H. and Graham, J. B.: Physiologic basis of transfusion therapy in hemophilia. Arch. Path. 61: 6 (1956).

3. Cohn, E. J.; Strong, L. E.; Hughes, W. L.; Mulfond, D. J.; Asworth, J. N.; Melin, M. and TAYLoR, H. L.: A system for the separation into fractions of the protein and lipoprotein components of biological tissues and fluids. $J$. amer. chem. Soc. 68: 459 (1946).

4. Davidson, C. S.; Epstein, R. D.; Miller, G. F. and Taylor, F. H. L.: Hemophilia. A clinical study of 40 patients. Blood 4: 97 (1949).

5. Nilsson, I. M.; Blomback, M. and von Franckev, I.: On an inherited autosomal hemorrhagic diathesis with antihemophilic globulin (AHG) deficiency and prolonged bleeding time. Acta med. scand. 159: 35 (1957).

6. Penner, J. A.: Plasma prothrombin activation in hemorrhagic disorders. Amer. J. clin. Path. 42: 561 (1964).

7. Penner, J. A.: Therapy for the hemophilic patient. Mich. Med. 63: 866 (1964).

8. Spaet, T. H. and Kinsell, B. G.: Properties of bovine antihemophilic factor. Proc. Soc. exp. Biol., N. Y. 84: 314 (1953).

Authors' addresses: Dr. J. T. Sgouris and Dr. L. A. Hyndman, Division of Laboratories, Michigan Department of Health, Lansing, Mich. and Dr. J. A. Penner, Department of Internal Medicine, Simpson Memorial Institute, The University of Michigan, Ann Arbor, Mich. (USA). 